\title{
Categorias espaciais: referentes an ensino de Geografia
}

\section{Spatial categories: concerning the teaching of Geography}

\section{Eduardo von Dentz* Adriana Maria Andreis ** Anelise Graciele Rambo ***}

\section{Resumo:}

Há diferentes modos de abordar o espaço geográfico e as categorias compõe esse processo, contribuindo para um ensino, pautado em supostos da educação geográfica. Nesse sentido, apresentamos argumentos acerca da relação com as categorias geográficas, que servem como instrumento à análise espacial no ensino de Geografia. Para o desenvolvimento da proposta, inicialmente esclarecemos o contexto discutindo a noção de espaço geográfico. Ao encontro dessa dimensão, debatemos a importância das categorias espaciais como corpus analítico que serve ao ensino da Geografia. Assumimos então uma discussão, argumentando acerca das categorias lugar, como a dimensão da existência que se manifesta no cotidiano, a paisagem como implicada naquilo que vemos e que os nossos sentidos alcançam, a região e o sentido de regionalização e das diferenças regionais, e o território e seu uso. Para essa discussão, utilizamos fotografias e mapas para discutir possibilidades ao ensino de Geografia, o que nos permite inferir que o uso desses recursos auxilia no processo de significação dos conhecimentos.

\section{Abstract:}

There are different ways of approaching the geographical space and categories make up this process, contributing to an education, based on supposed geographical education. In this sense, we present arguments about the relationship with the geographical categories, which serve as a tool for spatial analysis in the teaching of geography. For the development of the proposal, initially we clarify the context by discussing the notion of geographical space. The date of this dimension, we discussed the importance of spatial categories as analytical corpus that serves the teaching of geography. We assume so a discussion, arguing about the categories place, like the dimension of existence that manifests itself in daily life, the landscape as implicated in what we see and that our senses reach, the region and the sense of regionalization and regional differences, and the territory and its use. For this discussion, we use photographs and maps to discuss possibilities to the teaching of geography, which allows us to infer that the use of these features helps in the process of signification of knowledge.
* Graduado em Geografia pela Universidade Federal da Fronteira Sul (UFFS - Campus Chapecó). Mestrando em Geografia na Universidade Estadual do Oeste do Paraná (UNIOESTE - Campus Francisco Beltrão).

** Doutora em Educação nas Ciências pela Universidade Regional do Noroeste do Estado do Rio Grande do Sul (UNIJUI). Professora na UFFS - Campus Chapecõ.

*** Doutora em Desenvolvimento Rural pela Universidade Federal do Rio Grande do Sul (UFRGS). Professora adjunta no Departamento Interdisciplinar da UFRGS Campus Litoral Norte.

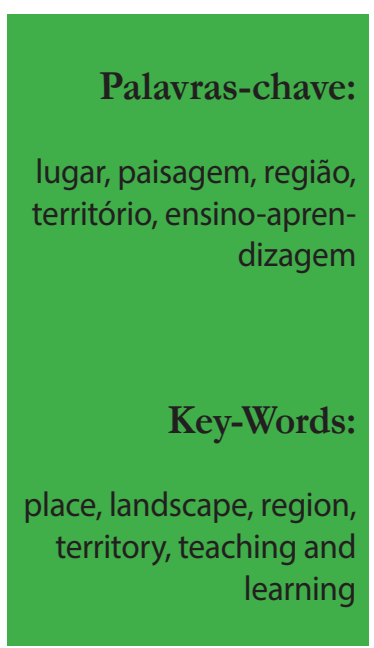




\section{INTRODUÇÃO}

$\mathrm{O}$ presente trabalho se constitui como uma reflexão teórica, envolvendo algumas categorias que compõem o corpus analítico da Geografia (SANTOS, 1997), interessado em pensar possibilidades de ensino-aprendizagem. Para isso, trabalhamos com algumas das mais importantes categorias geográficas: lugar, paisagem, região e território, que podem servir à análise espacial. Consideramos nesta proposição, que essas dimensões se configuram como modos de abordar a espacialidade. Assumindo esse sentido, que implica uma abordagem hermenêutica, colocamos acento nessas noções, na perspectiva de um debate que interessa ao ensino de Geografia e ao estudo sobre as categorias geográficas.

O objetivo central da discussão, é a construção de um complexo argumentativo acerca das diferentes categorias geográficas, para expressar algumas possibilidades, que podem auxiliar no cotidiano da sala de aula. Com esse sentido, organizamos o texto em partes que dialogam entre si. Começamos com uma breve reflexão sobre a relação entre espaço e ensino de Geografia; em seguida tratamos da categoria lugar como dimensão da existência que se manifesta através de um cotidiano; depois abordamos a categoria paisagem, englobando nela, aquilo que vemos e que os nossos sentidos alcançam; na sequência, a abordagem acontece sobre a categoria região, tratando da regionalização e das diferenças regionais; e, por último, mas não menos importante encaminhamos a pesquisa com a discussão sobre a categoria território, que terá um viés relacionado ao poder e ao uso do território. Essa argumentação teórica, elaboramos em diálogo com o campo empírico, utilizando fotografias e mapas, por meio dos quais expressamos exemplificações, que podem, também, ser entendidas como possibilidades pedagógicas às aulas de Geografia.

A elaboração abre um olhar para cada categoria em sua particularidade, até porque Milton Santos já esclarecia que um esforço analítico impõe que separemos o espaço geográfico em categorias diferentes, se não quisermos correr o risco de não reconhecer o movimento da sociedade (SANTOS, 1996). Pretendemos assim, argumentar teoricamente essas noções, discutindo a importância da clareza, para seu uso no ensino de Geografia na Educação Básica.

\section{ESPAÇO GEOGRÁFICO E CATEGORIAS QUE SERVEM AO ENSINO}

Ensinar Geografia implica no esforço de elaboração da análise espacial pelo viés geográfico. Para esse movimento as categorias servem para colocar em questão, o mundo tratado como objeto de pensamento, na aula de Geografia. Segundo Cavalcanti (2011), as categorias geográficas em sala de aula, servem ao processo de pensar.

Construir conhecimento geográfico, na perspectiva de uma educação geográfica, é uma tarefa que requer que o professor tenha entendimento do que implicam essas categorias geográficas, para, assim, poder propor discussões e problematizações em sala de aula, que estabeleçam relação com a vida dos sujeitos estudantes, que é espacial. Considerando essa relevância, destacamos inicialmente, os pressupostos que compõe as reflexões envolvendo o espaço geográfico.

\subsection{A noção de espaço geográfico}

Se no espaço geográfico é possível depreender categorias como lugar, paisagem, região e território, então, antes de tudo, é importante, refletir sobre o que é espaço no âmbito da Geografia. Para Santos (2012), entre as questões paralelas à questão principal, surgem mais frequentemente algumas que assim poderíamos resumir:

O que caracteriza, particularmente, a abordagem da sociedade através da categoria espaço? Como, na teoria e na prática, levar em conta os ingredientes sociais e 'naturais' que compõe o espaço para descrevê-lo, interpretá-lo, e afinal, encontrar o espacial? (SANTOS, 2012, p. 11), [grifo dos autores].

As indagações do estudioso da Geografia são importantes nesta pesquisa, pois permitem refletir sobre concepções extremamente importantes, que norteiam a ideia de espaço, ajudando a entender a complexidade do espaço geográfico para o ensino de Geografia. Mais do que isso, orientará a postura do cidadão, quiçá suas ações, no contexto das questões socioculturais, político-econômicas e ambientais, pois abre à compreensão numa perspectiva de totalidade.

Para Santos (2012), a resposta às questões que propõe "é, sem dúvida, árdua, na medida em 
que o vocábulo espaço se presta a uma variedade de acepções" (p. 11). O espaço, portanto, deve ser considerado como uma totalidade, sobretudo para que seja possível pensar no papel da Geografia na perspectiva apresentada por Andrade (1992, p.19):

Cabe a geografia, estudando as relações entre a sociedade e a natureza, analisar a forma como a sociedade atua, criticando os métodos utilizados e indicando as técnicas e as formas sociais que melhor mantenham o equilíbrio biológico e o bem- estar social [...] devendo indicar caminhos à sociedade, nas formas de utilização da natureza.

O que vamos aqui privilegiar, através do que chamamos "os elementos do espaço ou categorias do espaço" são apenas algumas das inúmeras possibilidades que temos de conceber, interpretar e atuar sobre o espaço.

Suertegaray (2001) propõe o espaço como "uno e múltiplo". Indo ao encontro do que a pesquisadora propõe, entendemos que essa perspectiva se sustenta a importância das categorias geográficas para o ensino de Geografia, de modo especial na Educação Básica. É irrelevante trabalhar as categorias de lugar, paisagem, região e território, desconexas do conceito de espaço geográfico, por exemplo. Visualizamos nestas categorias uma perspectiva balizadora da Geografia sob diferentes óticas do espaço geográfico, ou seja, cada categoria expressa uma possibilidade de leitura do espaço geográfico delineando, portanto, um caminho metodológico e a possibilidade de provocar à reflexão acerca da espacialidade, a partir de distintas abordagens.

Além de compreender os pressupostos, que envolvem cada categoria, é importante relacionar essas categorias com o mundo vivido. Por isso, trataremos cada uma das categorias colocando acento nas singularidades que as configuram e ilustramos esses modos de abordar, utilizando imagens e mapas. Começamos com o lugar.

\section{LUGAR}

Tendo presente as contribuições de Santos (2012) acerca do entendimento da noção de espaço e de espaço geográfico, realizaremos uma discussão focada na categoria lugar. Para isso, consideramos a proposição de Cavalcanti (1998), e destacamos dois modos de pensar o lugar: na perspectiva histórico-dialética e na perspectiva humanística'.

Como se trata de uma categoria geográfica é importante argumentar sistematicamente acerca da sua sustentação teórica. Assim, para abordar perspectivas de entendimento de lugar, inicialmente, cabe atentar aos alertas dos pesquisadores, acerca das interpretações envolvendo essa dimensão espacial. Corrêa (2007) refere que é importante considerar que há o risco de se reter ao uso corrente da relação e até mesmo da confusão com a palavra espaço, seu uso corriqueiro e, também, por diversas ciências. "Adicionalmente a palavra espaço tem o seu uso associado indiscriminadamente a diferentes escalas: global, continental, regional, da cidade, do bairro, da rua, da casa e de um cômodo no seu interior" (CORRÊA, 2007, p. 15). Ao encontro dessas assertivas, Cavalcanti (2011) chama a atenção para a necessidade de "ultrapassar a ideia desse conceito como simples localização espacial absoluta" (p. 89).

Atentando para a necessidade de focar no sentido atribuído à categoria de lugar, Suertegaray (2001) a aborda enquanto uma categoria operacional em Geografia.

\begin{abstract}
Consistiria, a partir da Cartografia, a expressão do espaço geográfico na escala local; a dimensão pontual. Por muito tempo, a Geografia tratou o lugar nesta perspectiva e considerou-o como único e autoexplicável. Recentemente, o lugar é resgatado na Geografia como conceito fundamental, passando a ser analisado de forma mais abrangente (SUERTEGARAY, 2001, p. 6).
\end{abstract}

É nesse sentido dotado de abrangência teórica, que a perspectiva histórico-dialética é argumentada por Santos (1997). Para o pesquisador, o lugar constitui uma parcela de espaço na dimensão da existência que se manifesta através de um cotidiano compartilhado entre os mais diversos tipos de pessoas, empresas, instituições - onde cooperação e conflito são à base da vida comum dessas pessoas. Para Cavalcanti (2011) o lugar implica em uma tensão contraditória entre a homogeneização e fragmentação (diferenciação e antagonismos). Trata-se de entender o lugar não como um isolado. Para a autora, o lugar sofre os impactos e realiza resistências.

Considerando essa dialética, Santos (1997) ressalta que esta relação era local-local, mas que se transformou em local-global. Portanto, a cate- 
goria lugar refere-se a um tratamento geográfico do mundo vivido. Trata-se, por isso, de darmo-nos conta de que não estamos sozinhos no mundo. $\mathrm{O}$ lugar onde vivemos implica relações e coexistência, tanto local-local quanto local-global.

A perspectiva humanística considera o lugar como "aquele que se torna familiar ao indivíduo, é o espaço do vivido do experienciado" (CAVALCANTI, 2011, p. 89). Para Tuan (1983), a compreensão de lugar, implica em elo de sentidos e significados espaciais, as ideias de um grupo ou povo sobre o espaço, a partir da experiência com este espaço. Trata-se de entender o mundo humano através do estudo das relações das pessoas com a natureza, do seu comportamento geográfico bem como dos seus sentimentos e ideias a respeito do espaço e do lugar (TUAN, 1983, p. 89).

Essas discussões nos permitem assumir o lugar como ponto nodal de "confroencontro" (ANDREIS, 2014) entre sujeitos, que produz espaço geográfico. Uma noção que vincula o onde às singularidades produzidas na interação entre natural e social. Noções, que servem à abordagem do lugar, no ensino de Geografia.

\subsection{A noção de espaço geográfico}

A imagem que segue nos possibilita refletir sobre as perspectivas de lugar, especialmente, como dimensão dialética e humanística. Ambas as dimensões, implicam um lugar no qual os sujeitos e entre eles, são colocadas no centro do debate.

Escolhemos uma imagem para tensionar possibilidades ao ensino de Geografia. Neste caso, conforme aparece na Figura 1, o lugar é tido como local em que as pessoas podem usufruir de um serviço público, mas pago, de transporte coletivo. O terminal urbano acaba se tornando um lugar de encontro e reencontro de muitas pessoas que o utilizam diariamente. Criam-se redes de relações pessoais e interpessoais. O terminal urbano é um lugar que nos remete aos sentidos espaciais, pois este lugar se transforma num lugar do espaço vivido das pessoas. A rotina de esperar o ônibus e de existir um terminal urbano como ponto de referência para aguardar a chegada do transporte, significa que podemos identificar na parada de ônibus um lugar onde pessoas diferentes se direcionam para um objetivo comum.

Neste sentido, o mundo vivido daqueles que utilizam o terminal urbano, ou até mesmo o próprio ônibus (transporte coletivo), diz respeito à afirmação de uma identidade que os une como pessoas que estão ali por um mesmo objetivo: se locomover para outro lugar. Tal é o mundo vivido por essas pessoas que nós podemos identificar, no espaço vivido, a identidade de lugar compartilhado entre o conjunto de pessoas que utilizam o terminal urbano.

É preciso focar nas duas perspectivas que nos referimos, ou seja, "histórico-dialética e humanística" e citar os autores para se referir à figura. Neste sentido, Suertegaray (2001), também ressalta que a categoria lugar pode ser trabalhada na perspectiva de mundo vivido. Por tal razão, no lugar, nosso próximo, se superpõe dialeticamente ao eixo das sucessões, que transmite os tempos externos das escalas superiores e o eixo dos tempos internos, que é o eixo das coexistências, onde tudo se funde, enlaçando definitivamente, as noções e as realidades de espaço e tempo.

Esse argumento reforça a compreensão de mundo vivido local-global. Para a autora Suertegaray (2001), o lugar expressa relações de ordem objetiva em articulação com relações subjetivas, relações verticais resultado do poder hegemônico, imbricadas com relações horizontais de coexistência e resistência. Daí a força do lugar no contexto atual da Geografia. Daí a relação estabelecida sobre o local-global.

O entendimento da categoria lugar trazido por Costa (2010) dá ênfase ao mundo vivido. Corroboramos com o autor quando ressalta que:

O conceito de lugar, dentro da geografia tradicional, foi definido de acordo com as características naturais e culturais próprias de uma determinada área. Estava ligado à noção de localização e à individualidade das parcelas do espaço. De acordo com Cavalcanti (2011), na perspectiva da geografia humanística o lugar é o conceito chave, compreendido com o espaço vivido. É onde a vida se realiza, está carregado de afetividade e significado. A perspectiva humanística é desenvolvida sobre as bases teóricas da fenomenologia, que tem na percepção do sujeito sobre o objeto a principal referência. Assim, o lugar é estudado a partir das relações e ligações subjetivas estabelecidas entre o sujeito e o espaço (COSTA, 2010, p. 27). 




Figura 1:Terminal de ônibus urbano de Chapecó-SC. Fonte: arquivo pessoal, 25/09/2015.

O lugar é o espaço do particular, estando presentes os elementos históricos, culturais e a identidade; revelando as especificidades. É no lugar que se materializam as contradições da globalização, que podemos observar as relações local-global, conforme suas particularidades e suas possibilidades.

Ademais, no lugar onde acontecem as mais diversas articulações de organizações dos sujeitos, como movimentos populares, cooperações entre empresas, movimentos sociais, enfim, entidades com uma mesma finalidade capaz de organizarem-se em prol de um objetivo comum, o sentido e o significado do lugar ganham força.

O lugar, portanto, torna-se um elemento fundamental. Por mais que seja "qualquer espaço", o ponto de encontro/reunião dessas entidades se torna importante na medida em que agrega valores, significado e vivências para quem o vive. A existência que se manifesta através de um cotidiano e um significado é um importante elemento que nos auxilia na reflexão acerca das relações de identidade do sujeito para com seu lugar. Compreender e interpretar esta relação de identidade é fundamental para atuarmos sobre o espaço geográfico, seja na sociedade em geral, seja na escola. Neste sentido, citamos a afirmação de Cavalcanti (2011), de que o lugar é aquele que se torna familiar ao indivíduo, é o espaço do vivido, do experienciado.

Neste sentido, como a Figura 1 pode ser usada em uma aula de Geografia? As possibilidades são inúmeras. No entanto, vale ressaltar, bem como foi argumentado na revisão teórica acerca da categoria lugar, que a Figura 1 pode ser usada como possibilidade argumentativa e interrogativa com os alunos. O professor pode levar a imagem impressa ou mesmo projetar através de equipamento multimídia, quando possível, e usar a imagem como base para indagar aos alunos se podemos identificar no terminal urbano da cidade de Chapecó um lugar usado por várias pessoas que se dirigem até ele por um objetivo comum: se deslocar para outros lugares da cidade. Nesta perspectiva, serve como um recurso para indagações e elaborações teóricas, que visam à construção de relações com diferentes conceitos geográficos.

Na sequência, queremos dar ênfase a categoria paisagem. Dessa forma, poderíamos utilizar a Figura 1, para pensar também a paisagem. Porém, para servir como uma possibilidade pedagógica diferente, optamos por apresentar uma discussão sobre esse conceito e propor outras imagens (Figuras 2 e 3), complexificando assim a reflexão acerca da categoria paisagem. 


\section{PAISAGEM}

A categoria paisagem na Geografia, tanto para Costa (2010) quanto para Suertegaray (2001), parte do princípio de uma suposição natural, ou seja, agregada a elementos de cunho natural (clima, relevo, vegetação, solo, hidrografia, entre outros). No entanto, com o passar do tempo, tendo em vista a história do pensamento geográfico, Santos (1997) denomina "paisagem como expressão materializada do espaço geográfico, interpretando -a como forma" (SUERTEGARAY, 2001, p. 5). Ou seja, podemos analisar a paisagem como a materialização das condições sociais.

Para Costa e Rocha (2010), "a paisagem surge na Geografia como uma das primeiras categorias basilares e desenvolve-se sob variadas perspectivas teórico-conceituais e metodológicas, circunstanciadas pelo momento histórico atravessado" (p.25). Neste sentido, corroborando com o autor, em geral, para os geógrafos, a categoria paisagem é entendida como as expressões materializadas das relações entre homem e natureza. $\mathrm{O}$ significado de paisagem remete inicialmente à forma, porém, vai além do alcance da visão. A paisagem, portanto, é a expressão - visível e invisível - resultante das relações.

Uma questão importante, conforme coloca Suertegaray (2001), é não confundir paisagem com natureza. São conceitos diferentes. "A natureza não é paisagem. A natureza existe em si, enquanto que a paisagem existe somente em relação ao homem, na medida em que a elabora historicamente" (SUERTEGARAY, 2001, p. 26). Mas a natureza compõe a paisagem. Com relação à paisagem natural, Ab'saber foi um dos geógrafos brasileiros que mais contribuiu para o desdobramento do termo, recuperando a categoria paisagem a partir da Geografia Física, mais especificamente em seus estudos geomorfológicos. Para Ab'saber (2003) a paisagem pode ser entendida como um princípio dinâmico, espacial e histórico em interação com as diversas escalas atuantes no modelado terrestre. Em Santos (1986), "encontramos que a paisagem é tudo o que é visível, o que a visão alcança que a vista abarca. É formada por cores, odores, sons e movimento. É o materializado de um instante da sociedade" (COSTA e ROCHA, 2010, p. 26). Neste sentido, Santos (1997) ressalta que "paisagem é o conjunto de formas que, num dado momento, exprimem as heranças que representam as sucessivas relações localizadas entre o homem e a natureza. Ou ainda, a paisagem se dá como conjunto de objetos reais concretos" (SUERTEGARAY, 2001, p. 5). Ou seja, a categoria paisagem é indissociável ao conjunto histórico da Geografia.

Atualmente se verificam na Geografia duas correntes identificadas com o estudo da paisagem. Segundo Suertegaray (2001), uma enfatiza as múltiplas relações entre os elementos naturais (clima, relevo, solo, vegetação, geologia e hidrografia) associadas às ações antrópicas como os fatores responsáveis pela morfologia da paisagem. Esta corrente foi denominada sistêmica ou geossistêmica. A outra corrente prioriza a cultura humana e foi denominada paisagem cultural (SUERTEGARAY, 2001).

A visão sistêmica foi desenvolvida na Geografia por Soctchava na década de 1960. Em seguida o francês Bertrand define recortes espaciais e escala de análise. Na perspectiva cultural é analisado o vínculo que o homem estabelece com o lugar, (SUERTEGARAY, 2001) tal como apresenta, por exemplo, Berque $(1990,1997)$.

Neste sentido, a paisagem pode ser identificada como natural mais a ação antrópica que modifica a morfologia desta paisagem e, como cultural, mais o vínculo estabelecido entre o homem e o lugar. Embora se possa priorizar uma das dimensões, a distinção entre paisagem natural e cultura não é clara nem evidente, considerando, sobretudo, a perspectiva da totalidade do espaço geográfico. Nas Figuras que seguem (2 e 3) podemos identificar as duas perspectivas citadas, bem como o complexo espacial presente na paisagem.

A Figura 2 pode representar uma paisagem na qual se sobressaem no primeiro plano os elementos da vegetação e do relevo. Visualizam-se algumas árvores e capões de mato mais ou fundo, bem como a vegetação rasteira e seca, por ser inverno. As formas mais artificializadas podem ser visualizadas ao fundo e na porção direita da figura, onde é possível identificar a concentração urbana da porção leste da cidade de Chapecó, fruto da ação antrópica. Ao irmos além da aparência da paisagem, criamos a possibilidade de analisar como está se dando a relação homem-meio neste recorte espacial, tornando-se 




Figura 2: Paisagem em Chapecó-SC.

Fonte: arquivo pessoal, 24/05/2014.

uma perspectiva didático-pedagógica interessante. Analisar, por exemplo, em que medida a paisagem que aparece ao fundo e na porção do lado direito da figura influencia o ambiente mais natural - a mata considerado tão importante, sobretudo para a preservação de nascentes e da própria mata. Assim, o professor pode questionar seus alunos sobre como as relações de identidade, do cotidiano e da existência (na perspectiva da categoria de lugar) podem influenciar a modificação da paisagem.

A imagem a seguir denota uma paisagem mais artificializada, na qual as formas naturais são menos expressivas e os problemas socioeconômicos parecem evidentes. No senso comum, nem sempre a figura 03 seria compreendida como uma paisagem, muitas vezes tida como algo bonito aos sentidos. No entanto, para a Geografia, esta paisagem é um profícuo ponto de partida para discutir e analisar os processos, as funções e as estruturas que dão forma a essa paisagem.

Enquanto a Figura 3 possibilita a vista de uma considerável concentração de prédios na área central da cidade de Chapecó, onde reside a maioria das pessoas que possuem grande poder aquisitivo, sabemos que, mesmo que este cenário não apareça na Figura 3 , nos locais mais periféricos e onde a verticalização da cidade é menos expressiva residem famílias de baixa renda, muitas vezes excluídas do fornecimento de lazer e cultura que a parte central da cidade pode usufruir. Ou seja, uma parte do que chamamos de paisagem cultural é detentora das oportunidades de acesso aos mais diversos tipos de lazer, cultura, educação, saúde e diversão, por exemplo; e a outra parte é simplesmente impedida de ter acesso a essas "regalias" que apenas quem possui significativa renda é capaz de usufruir. Estas formas expressas na figura três, dentre outras questões, podem expressar o estudo da verticalidade da cidade e da concentração urbana. Ademais, a discussão do visível e do invisível pode ser potencializada a partir da Figura 3.

Enfim, a paisagem não revela apenas as relações de produção da sociedade, a estrutura da sociedade, mas também o imaginário social, as crenças, os valores, as discrepâncias, os sentimentos das pessoas que a constroem. A paisagem deve ser pensada paralelamente às condições políticas, econômicas e também culturais (SANTOS, 1996) para compreendermos como as sociedades fazem uso 


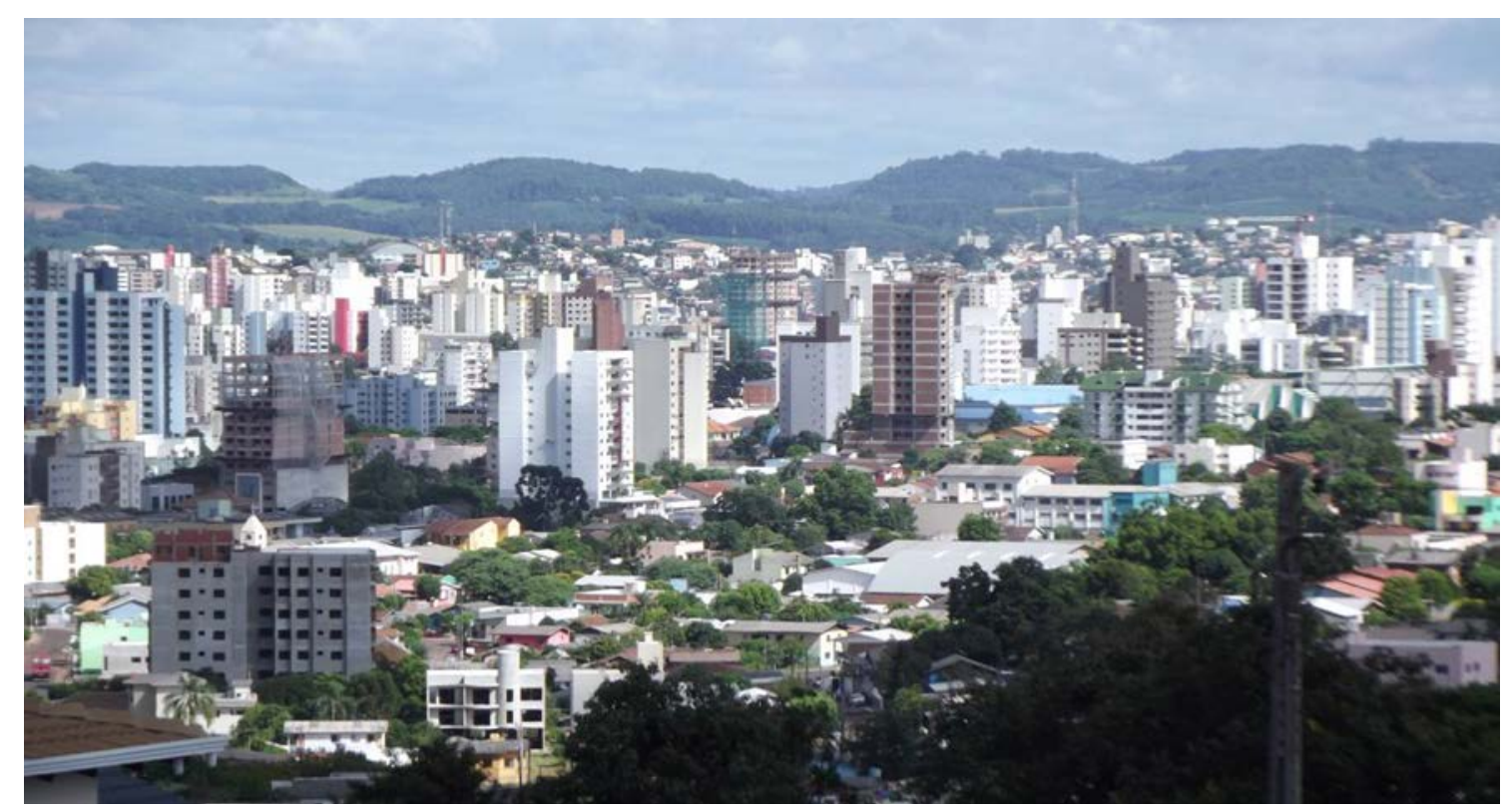

Figura 3: Vista parcial da cidade de Chapecó-SC. Fonte: arquivo pessoal, 25/03/2014.

do espaço e os reflexos desse uso. Chamar a atenção dos estudantes para isso é fundamental para a relação com os conceitos geográficos e também para a formação de cidadão críticos.

Com isso, de acordo com Costa (2010), o que fica em evidência é o fato de a paisagem ser uma importante e dinâmica categoria no âmbito da Geografia, adquirindo interpretações próprias e particulares em conformidade com os paradigmas e teorias nas quais foi gerada.

Assim como todos os lugares tem paisagens, também, podem ser pensados na perspectiva da região. É o que a seguir nos dedicamos, pensando em uma argumentação acerca da sustentação teórica da noção de região e, também, interessados em oferecer reflexões que sirvam ao ensino de Geografia.

\section{REGIÃO}

A categoria região foi amplamente discutida pela escola francesa e está associada à noção de diferenciação e identificação de áreas, segundo critérios escolhidos. Sua etimologia remete a uma área sob determinado domínio ou área definida pela regularidade de propriedades que a definem. A noção de região abarca três grandes domínios classificatórios: o domínio do conhecimento do senso comum, o domínio da administração e o domínio do conhecimen- to científico, este apropriado em grande medida pela Geografia (GOMES, 2003). Também, de acordo com Costa (2010),

O conceito de região foi amplamente difundido na geografia, sendo considerado por alguns pesquisadores, como é o caso de Hartshorne, um método para o estudo da geografia. No entanto, na última década no Brasil, o conceito tem ficado em segundo plano nas discussóes. Maior ênfase passou a ser dada aos conceitos paisagem, território e lugar. Mesmo assim, os estudos regionais ainda estão inseridos em um considerável número de pesquisas que contribuem para o desenvolvimento do pensamento geográfico (COSTA, 2010, p. 49).

Tal como sistematiza Santos (1986), na Geografia Tradicional, a região remetia a recortes naturais ou dados pela paisagem. O método de análise era descritivo e limites regionais eram bem definidos por fronteiras. Na Nova Geografia, a técnica estatística passa a revelar as regiões, que eram consideradas um conjunto de lugares onde as diferenças internas eram menores que as existentes em outro conjunto de lugares. Já no âmbito da Geografia Crítica e Humanista a região é considerada como uma das dimensões espaciais do processo desigual e combinado do capitalismo, devendo a região ser analisada a partir da caracterização desse processo, ou então, com ênfase na vertente historicista da Geografia, onde a região passou a ser considerada um espaço produto da história e da cultura. 
Hoje, segundo Santos (2012), a noção tradicional de região não pode resistir às configurações atuais das dinâmicas regionais. A concepção de região trabalhada por Milton Santos se enquadra na perspectiva da Geografia Crítica, sendo dada pelo viés do sistema capitalista. Segundo o autor, "dentro de uma região, os capitais fixos são geografizados segundo uma lógica que é a do momento de sua criação. Isso tem um inegável papel de inércia" (SANTOS, 2012, p. 89).

Santos (2012), argumenta que a cada momento histórico, uma determinada região aparece como o melhor lugar para a realização de certo número de atividades; ademais, no mundo contemporâneo, a categoria região vem ganhando força se relacionada à rede de fluxos econômicos que movimenta as dinâmicas econômicas regionais. Dessa forma,

A região se definiria, assim, como o resultado das possibilidades ligadas a uma certa presença, nela, de capitais fixos exercendo determinado papel ou determinadas funções técnicas e das condições do seu funcionamento econômiCo, dadas pela rede de relações (SANTOS, 2012, p. 90).

Neste sentido, na visão da Geografia Crítica se analisa a região como um espaço delimitado onde se promove o desenvolvimento desigual. "A região é considerada uma entidade concreta, resultado de múltiplas determinações e das contradições materializadas no espaço. O enfoque está dentro da temática centro e periferia" (COSTA, 2010, p. 38).

A partir da perspectiva da Geografia Crítica e particularmente, das contribuições que traz Milton Santos, podemos, portanto, reconhecer vários tipos de regiões: região agrícola, região urbana, região produtiva, região universitária, região escolar, região definida pelas vias de transporte, pelos fluxos aéreos, níveis de renda, exploração de recursos naturais, degradação ambiental e tantas outras. Esta categoria geográfica nos permite analisar o espaço geográfico pelas diferenças regionais decorrentes do desenvolvimento do sistema capitalista, que vale ressaltar, se dá em diferentes escalas.

Nesta perspectiva, utilizaremos um mapa ( $\mathrm{Fi}-$ gura 4), para essa reflexão. Nesta figura, aparecem diferentes mesorregiões (IBGE) do estado de Santa Catarina. Cada região é composta por cidades regionais com função econômica capaz de centralizar as atividades comerciais, políticas, educacionais, de saúde, de administração, de serviços, dentre outras; impulsionando a dinâmica do sistema capitalista em cada área de abrangência, em diferentes escalas. No entanto, embora sejam informações que não estejam aparentemente contidas neste mapa, nós sabemos que no interior de cada região existem processos que potencializam o desenvolvimento desigual. Estamos falando das múltiplas determinações e das contradições materializadas no espaço.

O desafio, no horizonte do ensino de Geografia, é como criar um método capaz de possibilitar aos alunos percepções geoespaciais que tornem visível as discrepâncias e contradições presentes no interior de uma mesma região. Também e, especialmente, que regionalizar implica em uma escolha de critério. Assim, um mesmo lugar pode ser pensado como integrante de diferentes regiões, dependendo do critério utilizado. Cientes dessas possibilidades, poderíamos nos perguntar, a partir da figura 04, o que a define como região? Dessa forma, no mapa obtido, é possível identificar as principais cidades de cada região do estado de Santa Catarina exibidas na figura 04. No entanto, na figura 05 , a partir de uma realidade ilustrada, podemos observar nitidamente um exemplo de diferenciação regional e socioespacial.

A Figura 5 é a situação na qual podemos identificar uma diferenciação regional e socioespacial. A figura compreende uma visão parcial da cidade de Chapecó, parte composta pela mancha urbana e parte composta por áreas não urbanizadas. Dessa forma, a imagem, numa devida capacidade interpretativa do sujeito, nos proporciona o entendimento de que existe uma diferença regional, que neste caso nos permite identificar e distinguir área urbana de área rural. Ademais, como bem salienta Santos (2012), a região é o lugar onde se realiza um número diferenciado de atividades. Neste sentido, sabemos da complexidade e do grande número de atividades que existe numa cidade e também na zona rural. Temos, portanto, na Figura 5, a diferenciação regional e socioespacial de áreas que se localizam na cidade de Chapecó. As singularidades, ou melhor, a exclusividade de cada lugar e a provisoriedade da paisagem, assegura que a região compõe apenas, uma eleição de fatores a serem destacados no mapa e na fotografia, por exemplo. 




Figura 4: Divisão regional do estado de Santa Catarina.

Fonte: Buffon, 2015. Organização dos autores.



Figura 5: Região em Chapecó-SC.

Fonte: arquivo pessoal. 18/03/2014. 
Em razão disso, evidencia-se a importância da categoria região para o ensino de Geografia bem como a usualidade dessa categoria geográfica para pesquisadores, professores e alunos, a fim interpretar as diferenças espaciais decorrentes do sistema capitalista. Lugar, paisagem e região, também tem implicada a noção de território, porque envolvem a noção de apropriação do espaço geográfico.

\section{TERRITÓRIO}

Nas últimas décadas, a categoria território vem sendo amplamente debatida entre os pesquisadores, principalmente da área da Geografia, mas não somente, existindo divergências nas formas de conceber o termo. No entanto, etimologicamente a palavra território - territorium - em latim, "é derivada do vocábulo terra e é compreendido como o pedaço de terra apropriado, dentro dos limites de uma jurisdição político-administrativa" (COSTA, 2010, p. 22).

Corroborando com Costa (2010), no Brasil, durante muito tempo a noção de território ficou restrita a uma porção de terra limitada por fronteiras. Mas hoje, o termo vem ganhando nova amplitude em razão de novos olhares sobre a temática baseados, entre outros, na multiplicidade de atores e poderes que transformam o território.

Quanto à perspectiva tradicional, Suertegaray (2001) ressalta que:

Sob o conceito de Território, tratamos o espaço geográfico a partir de uma concepção que privilegia o político ou a dominação-apropriação. Historicamente, o território na Geografia foi pensado, definido e delimitado a partir de relações de poder. No passado da Geografia, Ratzel (1899), ao tratar do território, vincula-o ao solo, enquanto espaço ocupado por uma determinada sociedade. A concepção clássica de território vincula-se ao domínio de uma determinada área, imprimindo uma perspectiva de análise centrada na identidade nacional. Afirmava Ratzel (1899), no que se refere ao Estado, a Geografia Política está desde há muito tempo habituada a considerar junto ao tamanho da população, o tamanho do território (SUERTEGARAY, 2001, p. 5).

De acordo com Castro (2011), a palavra território normalmente evoca o Território Nacional e nos faz pensar no Estado, ou seja, em grandes espaços, em sentimentos patrióticos, em governos e em dimensões. Nesta perspectiva, para Castro (2011), o território, na tradicional Geografia Política, como o espaço concreto em si (com seus atributos naturais e socialmente construídos), é apropriado e ocupado por um grupo social. A ocupação do território é vista como algo gerador de raízes e identidades, sendo que um grupo não pode mais ser compreendido sem o seu território, no sentido de que a identidade social-cultural das pessoas estaria intimamente ligada aos atributos do espaço concreto (natureza, patrimônio arquitetônicos, paisagem) e isto, por sua vez, implica falar em território.

Para além da perspectiva tradicional, Haesbaert (2011) aponta que, de modo geral, na Ciência Geográfica há três vertentes básicas de concepção de território, sendo elas a política, a cultural e a econômica. A vertente política destaca as relações espaço-poder e concebe o território como espaço delimitado e controlado, muitas vezes relacionado ao poder político do Estado, porém, atualmente incorpora múltiplos poderes. A cultural entende o território como produto da apropriação e da valorização simbólica de um grupo em relação ao espaço vivido, ao cotidiano. E a econômica o considera como fonte de recursos ou como produto da divisão territorial do trabalho.

$\mathrm{O}$ autor defende ainda uma perspectiva integradora ou relacional que parte do pressuposto de que não há vida sem, ao mesmo tempo, atividade econômica, poder político e criação de significado, de cultura. Por conseguinte, o território é concebido a partir da imbricação de múltiplas relações de poder, ora mais material, das relações econômicas e políticas, ora mais simbólico, das relações culturais (HAESBAERT, 2011).

Ademais, Santos (1997) aborda a categoria de território sob a perspectiva de uso. Para o autor, "o território usado constitui-se como um todo complexo onde se tece uma trama de relações complementares e conflitantes. Sugere que o foco das análises seja o território usado e não o território em si" (SANTOS; SILVEIRA, 2001). Na Figura 6 que segue, podemos identificar uma forma de expressão do poder no espaço público de Chapecó. As placas indicando que o estacionamento é de uso privativo é uma contradição à lógica de uso de dado território, se considerarmos que a rua é um espaço público e de livre circulação. Embora sejamos conscientes de que em locais como hospitais e farmácias há essa 




Figura 6: Placas indicando uma forma de poder no espaço público de Chapecó-SC. Fonte: arquivo pessoal. 19/05/2014.

tendência de fracionar o tempo de uso do espaço (ou seja, tempo máximo de parada para veículos), entendemos que a placa que está mais abaixo na figura 06 expressa nitidamente as relações de poder e de força existente neste local, pois se o cliente da farmácia passar do tempo estipulado na placa, seu carro será guinchado; sendo que este território, em tese, por ser na rua, é público.

O fato de nesta localidade existir uma farmácia, torna o uso do território desta localidade reduzido e restrito, expressando um ato de relações de força que existe na vida urbana. Isto é, a categoria território está presente no que as placas simbolizam, pois o fato de elas estarem dizendo que o estacionamento é privativo e limitado expressam poder e por isso, indicam que há restrição para o uso do espaço. Assim, tornase pertinente ressaltar que ao definirmos uma forma de compreender a categoria território, precisamos tomar cuidado para não confundir tal compreensão apenas com a perspectiva política desta categoria, mas sim de uma forma mais abrangente.

Essa figura aponta para o território numa perspectiva de uso. Ela serve para indagar acerca da importância do poder (e das diferentes formas de po- der: político, econômico, social) na constituição das diferentes formas de uso do território. Cabe destacar, que a imagem utilizada, enunciando o limite proibitivo em frente a uma farmácia, compreende parte de uma prerrogativa legal de reserva de estacionamento (pertinente e justificado), em frente a locais relacionados com o sistema de saúde. Ainda assim a inserimos, como ilustrativa de território, também, por indiciar singularmente as "relações de força" uma vez que há duas informações contraditórias impressas nas placas: uma informando ser permitido estacionar por 30 minutos (placa pública - municipal), e outra admitindo apenas 50\% do tempo, ou seja, 15 minutos (placa privada - farmácia). Essas informações destacam diferentes interesses que estão em questão. Pode-se entender, por exemplo, que o poder público, atendendo a legislação, reserva maior tempo de estacionamento para o conforto da pessoa que necessitar adquirir medicamentos. A farmácia, por sua vez, deseja que a circulação de pessoas seja mais ágil, pois o interesse é que maior número de pessoas possam acessar o estabelecimento.

Utilizamos ainda a Figura 7, para tensionar a categoria território. Trata-se de um mapa, que per- 




Figura 7: Fluxo econômico por entroncamento rodoviário no território do estado de São Paulo, em $2002^{2}$. Fonte: Ichihara, 2007. Disponível em: <http://www.ub.edu/geocrit/sn/sn-283.htm>.

mite pensar o território, destacando as fronteiras econômicas no estado de São Paulo.

Podemos verificar que a região administrativa de Campinas, por exemplo, a partir de uma interpretação do uso do território, concentrou $25 \%$ dos fluxos econômicos do estado de São Paulo. Sua conexão com as indústrias do interior do estado se faz por duas importantes rodovias: a Anhanguera e a Bandeirantes. A Anhanguera é a rodovia paulista que apresenta, depois do Complexo Anchieta-Imigrantes, o maior fluxo econômico e faz a conexão das indústrias da região de Campinas com as da região de Ribeirão Preto e também faz a conexão de Franca com o Triângulo Mineiro - na aproximação com a fronteira mineira há uma perda de intensidade, que continua na direção norte do território brasileiro.

A Região Administrativa de Sorocaba, a maior em extensão territorial, possui duas importantes rodovias, ou seja, a Castelo Branco e a Raposo Tavares. O fluxo econômico pela rodovia Castelo Branco é mais intenso que pela rodovia Raposo Tavares, devido à dinâmica econômica ser mais intensa e também às melhores condições de infraestruturas da rodovia.

A partir desta dinâmica de distribuição e de crescimento do setor econômico no território do estado de São Paulo, analisado na Figura 7, podemos ver como o território se torna, de certa maneira, uma forma de rede, interligando as regiões produtivas aos centros consumidores e exportadores. Temos, portanto, um exemplo de território dos fluxos, tendo em conta a questão econômica do estado de São Paulo. Esta, por sua vez, é uma forma de entender o uso do território, isto é, a partir da perspectiva econômica.

Podemos perceber, conforme as análises de Castro (2011), Costa (2010), Suertegaray (2001), Santos (1997), que a categoria território tornou-se mais complexa e abrangente, estando relacionada ao uso, a apropriação do espaço, as relações sociais, políticas, econômicas, culturais, simbólicas de poder e de controle. O território ganhou novas perspectivas em virtude das possibilidades de abordagem estabelecidas sobre o tema por importantes estudiosos, ao observarem a complexidade das relações de poder expressas sobre o território.

Na proposta de dialogar com o ensino de Geografia, que também é uma tarefa complexa, escoIhemos figuras (fotografias e mapas) que podem auxiliar. Neste sentido, é pertinente à discussão dizer que o mapa é um instrumento indispensável para entender o que é território, mas não é o único, pois o mapa é um meio de compreensão da categoria em análise, e não um fim. Por isso, na figura 06 nós podemos entender território numa perspectiva de imagem (figura) concreta de algum lugar - no caso, a imagem se refere a cidade de Chapecó/SC -, mas na Figura 7, a partir de uma ótica política e econô- 
mica que o mapa apresenta, é possível interpretarmos o mapa refletindo sobre o uso do território em diferentes perspectivas.

$\mathrm{O}$ avanço sobre o entendimento de território vem contribuindo para a produção de pesquisas críticas, para o ensino de Geografia na Educação Básica e para as preocupações com as relações estabelecidas a partir do uso e apropriação do mesmo. $\mathrm{O}$ que evidencia o caráter dinâmico da categoria e da própria Geografia como ciência.

Cabe a nós, portanto, incrementar na discussão da categoria território uma dimensão relacional, de redes e do uso do território. Haja vista que no mundo globalizado em que vivemos é difícil pensar um território desconexo de outro, apesar de fisicamente terem suas fronteiras bem delimitadas.

\section{CATEGORIAS GEOGRÁFICAS NO ENSINO DE GEOGRAFIA}

Ao lançarmos um olhar para o campo de trabaIho do geógrafo, veremos que ele, sobretudo se esforça por realizar o velho sonho do filósofo: apreender o real em sua totalidade e em sua complexidade. Neste sentido, é pertinente que agregamos às categorias de lugar, paisagem, região e território, bem como as formas de aplicação dessas categorias no ensino de Geografia, a dimensão de totalidade. É graças aos progressos conjuntos da ciência, da educação, da técnica e da informação, que a noção de totalidade permite um tratamento objetivo, porém complexo.

A categoria lugar, de acordo com o que discutimos anteriormente, está intimamente ligada a um local onde residem pessoas que buscam estabelecer entre si um sentimento de valor, significado e vivência. A categoria paisagem primeiramente dizia respeito a elementos naturais (clima, relevo, vegetação, hidrografia), mas com o tempo passou a ser entendida como as expressões materializadas da relação estabelecida entre o homem e a natureza. A categoria região, se discutida em torno do sistema capitalista, pode ser definida como um espaço onde se promove o desenvolvimento desigual. Por último, a categoria território poderia simplesmente ser balizada como uma porção de terra delimitada por fronteiras; contudo, sabemos que hoje essa categoria é extremamente importante e sua magnitude interpretativa se estende ao entendimento de que o território usado constitui-se como um todo complexo onde se tece uma trama de relações complementares e conflitantes que dizem respeito ao seu uso, poder, economia e política, por exemplo.

Em razão da construção de um escopo teórico sobre as categorias supracitadas, vimos como relevante destacar a importância de entender cada um dessas categorias como categoria do espaço geográfico e da totalidade geográfica.

Tão importante como compreendermos o que é o espaço geográfico é entendermos a noção de totalidade contida no mesmo. Neste sentido, quando nos damos conta de que existe uma importância significativa na compreensão do uso das categorias geográficas para o ensino de Geografia, estamos um passo adiante. Além disso, se tratarmos os fatos empíricos como uma estratégia de ensino de Geografia, sem dúvida estaremos usufruindo de uma metodologia acessível aos alunos para a capacidade de compreender claramente o significado de cada categoria; por isso, as figuras e mapas utilizados neste artigo retratam situações que potencializam o ato de ensinar e aprender Geografia. Ademais, as figuras tem relação fundamental com os sujeitos aprendentes, colocando-os em contato, através das figuras, em sala de aula, com o ambiente em que eles vivem.

Se no espaço geográfico nós somos capazes de identificar categorias como lugar, paisagem, região e território e discutir uma forma plausível de usá-las no ensino de Geografia; então nós conseguimos ter uma noção do que é espaço. $O$ espaço, portanto, deve ser considerado como uma totalidade. Privilegiamos aqui, através do que chamamos de elementos do espaço ou categorias do espaço (lugar, paisagem, região e território), apenas algumas das inúmeras possibilidades que temos de conceber esse termo. Importa que as categorias sejam internalizadas, mas não somente isso. É preciso agregar a elas uma capacidade argumentativa indagadora de novas questões, nas mais diversas áreas de abrangência da geografia como ciência.

A importância de realizar a análise pautandose em categorias implica numa forma simples, mas não pouco importante, de apresentar aos alunos uma maneira diferenciada de apreensão do conhecimento geográfico, pois implica em reflexões pros- 
pectivas, ou seja, que avança e complexifica as compreensões na aula de Geografia.

Além disso, falamos, nosso desafio nesse texto consistiu na construção de um embasamento teórico capaz de explicar a natureza associada das categorias geográficas e do ensino de Geografia. Neste sentido, tanto as categorias geográficas quanto o ensino de Geografia, implicam em modos de abordar a espacialidade. No entanto, isso não basta se não tivermos a capacidade interpretativa e analítica sobre os elementos e os problemas que compõe o espaço em si. Portanto, a análise de um elemento ou de um problema do espaço, deve sempre vir acompanhada de método.

As Figuras 1, 2, 3, 4, 5, 6 e 7 servem para pensar o espaço geográfico e para abordar as categorias de lugar, paisagem, região e território, na sala de aula, especialmente, na Educação Básica. É importante ter presente que o professor deve ser o provocador da reflexão, pois ele é que compreende sistematicamente essas noções teóricas. O trabalho com as categorias geográficas em sala de aula visa a reflexão acerca da relação entre o mundo da vida e as generalizações na forma de conceitos e categorias geográficas. Esse é o processo de construção de conhecimentos significativos aos sujeitos, por isso, um movimento que dialoga com a educação geográfica.

\section{REFERÊNCIAS BIBLIOGRÁFICAS}

AB'SABER, Aziz Nacib. Os domínios da natureza no Brasil: potencialidades paisagísticas. São Paulo: Ateliê editorial, 2003.

ANDREIS, Adriana Maria. A aula: um território produto-produtor de espaço. In: BONASTRA, Quim; VASCONCELOS JUNIOR, Magno; TAPIA, Maricarmen (eds.). In: XIII Coloquio Internacional de Geocrítica: El control del espacio y los espacios de control. Actas... Barcelona: Universidad de Barcelona, 2014b. Disponível em: <http://www.ub.edu/geocrit/xiii-coloquio/ xiii-coloquio-portada.htm >. Acesso em: 22 jan. 2015.

BERQUE, Augustin. Médiance de milieux em paysages . Paris: Geographiques Reclus, 1990.

BERQUE, Augustin. Paisagem-marca, Paisagem-matriz: elementos da problemática para uma geografia cul- tural. In: CORRÊA, R.L; ROSENDAHL, Z. (Org.). Paisagem, tempo e cultura. Rio de Janeiro: EdUERJ, 1998. p.84-91

CASTRO, Iná Elias de; GOMES, Paulo Cesar da Costa ; CORRÊA, Roberto Lobato (Orgs.). Geografia: conceitos e temas. 14 ${ }^{\mathrm{a}} \mathrm{Ed}$. - Rio de Janeiro-RJ; Bertrand Brasil, 2011.

CAVALCANTI, Lana de Souza. Geografia, escola e construção de conhecimentos. 18a Ed. - Campinas-SP; Papirus, 2011.

CORRÊA, Roberto Lobato. Região e organização espacial. 8a Ed. São Paulo: Ática. 2007.

COSTA, Fábio Rodrigues da; ROCHA, Márcio Mendes. Geografia: conceitos e paradigmas - apontamentos preliminares. Revista Geomae, Campo Mourão-PR, v.1, n.2, p.25 - $56,2010$.

GOMES, Paulo Carlos da Costa. O conceito de região e sua discussão. In: CASTRO, Iná E.; GOMES, Paulo C.; CORRÊA, Roberto L. Geografia: conceitos e temas. Rio de Janeiro, Bertrand Brasil, 2003, p. 49-76.

HAESBAERT, Rogério da Costa. O mito da desterritorialização: do 'fim dos territórios' à multiterritorialidade. 6 ed. ver. Rio de Janeiro: Bertrand Brasil, 2011.

HARVEY, David. O trabalho, o capital e o conflito de classes. São Paulo-SP, editorial Boitempo, 1998.

SANTOS, Milton. Metamorfose do Espaço Habitado. São Paulo: Hucitec, 1996.

SANTOS, Milton. A Natureza do Espaço. Técnica e Tempo. Razão e Emoção. $2^{\circ}$ Edição. São Paulo: Hucitec, 1997.

SANTOS, Milton. Espaço e Método. São Paulo-SP; Edusp, 2012.

SANTOS, Milton. Por uma geografia nova: da crítica de geografia a uma geografia crítica. São Paulo: Hucitec, 1986.

SILVEIRA, Marcio. Logística, sistemas de movimento, fluxos econômicos e interações espaciais no território paulista: uma abordagem para a geografia dos transportes e circulação. Scripta Nova - Revista electronica de geografía y ciencias sociales, v. XIII, n. 283, Universidad 
de Barcelona, 2009. Disponível em: <http://www.ub.es/ geocrit/sn/sn-283.htm>.

SUERTEGARAY, Dirce Maria. Espaço Geográfico uno e múltiplo. Scripta Nova - Revista electronica de geografía y ciencias sociales, n. 93, Universidad de Barcelona, 2001.

TUAN, Y.Fu. Espaço e lugar: a perspectiva da experiência. São Paulo: DIFEL,1983.

Notas de Fim:

1- Cavalcanti (1998) propõe três possibilidades de entendimento de lugar. Porém, assumimos que a terceira perspectiva "pela ótica do pensamento pós-moderno" (p. 90), deslocaria a pretensão inerente a esta pesquisa, que visa construir um diálogo com a escola, atribuindo generalidade ao lugar.

2- Vale chamar atenção que, dependendo das circunstancias de ensino em que se pretende usar o mapa da figura 07, ele pode não ser uma boa escolha para o ensino de Geografia. Primeiro porque seu foco é restrito ao fator econômico, deixando de lado outras questões relevantes que podem ser abordadas no estudo da categoria território. Ademais, o mapa não atende aos critérios básicos geográfico-cartográficos, pois não apresenta escala, não apresenta os limites fronteiriços e não apresenta a rosa dos ventos. Portanto, ao apontar essas questões, neste mapa, o desafio, no horizonte do ensino da Geografia é como criar métodos que possibilitem aos alunos percepções geoespaciais que estejam incluídas no mapa/figura, tal como ele é, pois muitas vezes, acaba sendo este o recurso que nos resta para trabalhar determinado conteúdo.

\section{Correspondência dos autores:}

Eduardo von Dentz

e-mail: eduardovondentz@hotmail.com

Adriana Maria Andreis

e-mail: adriana.andreis@uffs.edu.br

Anelise Graciele Rambo

e-mail: ane_rambo@yahoo.com.br

Artigo recebido em: 02/03/2015

Revisado pelos autores em: 18/09/2015

Aceito para publicação em: 30/09/2015 